\title{
Identification of Genetic Variants in 65 Obesity Related Genes in a Cohort of Portuguese Obese Individuals
}

\author{
Catarina Ginete ${ }^{1}$, Bernardo Serrasqueiro ${ }^{1}\left(\mathbb{D}\right.$, José Silva-Nunes ${ }^{1,2,3}$, Luísa Veiga ${ }^{1}$ and Miguel Brito ${ }^{1, *(D)}$ \\ 1 H\&TRC Health and Technology Research Center, Escola Superior de Tecnologia da Saúde de Lisboa, Instituto \\ Politécnico de Lisboa, 1990-096 Lisbon, Portugal; catarina.ginete@estesl.ipl.pt (C.G.); \\ bernardo.serrasqueiro@gmail.com (B.S.); silvanunes2004@yahoo.com (J.S.-N.); luisa.veiga@estesl.ipl.pt (L.V.) \\ 2 Department of Endocrinology, Diabetes and Metabolism, Centro Hospitalar Universitário de Lisboa Central, \\ 1150-199 Lisbon, Portugal \\ 3 NOVA Medical School/Faculdade de Ciências Médicas, New University of Lisbon, 1169-056 Lisbon, Portugal \\ * Correspondence: miguel.brito@estesl.ipl.pt; Tel.: +35-12-1898-0400
}

check for updates

Citation: Ginete, C.; Serrasqueiro, B.; Silva-Nunes, J.; Veiga, L.; Brito, M. Identification of Genetic Variants in 65 Obesity Related Genes in a Cohort of Portuguese Obese Individuals. Genes 2021, 12, 603. https://doi.org/ $10.3390 /$ genes 12040603

Academic Editor: Sujoy Ghosh

Received: 24 March 2021

Accepted: 15 April 2021

Published: 19 April 2021

Publisher's Note: MDPI stays neutral with regard to jurisdictional claims in published maps and institutional affiliations.

Copyright: (c) 2021 by the authors. Licensee MDPI, Basel, Switzerland. This article is an open access article distributed under the terms and conditions of the Creative Commons Attribution (CC BY) license (https:// creativecommons.org/licenses/by/ $4.0 /)$.

\begin{abstract}
Obesity is a major public health problem, which has a strong genetic component that interplays with environmental factors. Several genes are known to be implicated in the regulation of body weight. The identification of alleles that can be associated with obesity is a key element to control this pandemic. On the basis of a Portuguese population, 65 obesity-related genes are sequenced using Next-Generation Sequencing (NGS) in 72 individuals with obesity, in order to identify variants associated with monogenic obesity and potential risk factors. A total of 429 variants are identified, 129 of which had already been associated with the phenotype. Comparing our results with the European and Global frequencies, from 1000 Genomes project, 23 potential risk variants are identified. Six new variants are discovered in heterozygous carriers: four missense (genes ALMS1NM_015120.4:c.5552C>T; SORCS1-NM_001013031.2:c.1072A>G and NM_001013031.2: c.2491A>C; TMEM67-NM_153704.5:c.158A>G) and two synonymous (genes BBS1-NM_024649.4:c.1437C>T; TMEM67-NM_153704.5:c.2583T>C). Functional studies should be performed to validate these new findings and evaluate their penetrance and pathogenicity. Regardless of no cases of monogenic obesity being identified, this kind of investigational study is important when we are still trying to understand the aetiology and pathophysiology of obesity. This will allow the identification of rare variants associated with obesity and the study of their prevalence in specific populational groups.
\end{abstract}

Keywords: obesity; monogenic obesity; next-generation sequencing (NGS); obese women

\section{Introduction}

Obesity is a major public health problem. The World Health Organization estimated that in 2016 more than 650 million adults (13\% of the world's population) would be obese and 1.9 billion (39\% of the world's population) would be overweight [1]. In Portugal, it was estimated that in 2017, 22.3\% of the population was obese [2].

Obesity is a complex disease influenced by the interaction of genetic and environmental factors [3] and a major risk factor for the development of other conditions, such as type 2 diabetes mellitus, hypertension, cardiovascular diseases and even certain types of cancer. The presence of these severe co-morbidities is responsible for the increased risk of mortality in these individuals $[4,5]$.

Obesity can also be one of the phenotypic characteristics in syndromic diseases, such as the Prader-Willi syndrome, Bardet-Biedl syndrome or Albright's hereditary osteodystrophy, but this only accounts for a small percentage of obesity cases.

Moreover, cases of non-syndromic monogenic obesity are also very rare, accounting for less than 5\% of diagnoses in Europe [6]. Non-syndromic monogenic obesity may have a dominant or recessive inheritance, resulting from a pathogenic mutation in genes with an essential role in maintaining energy homeostasis by participating in the leptin-melanocortin 
signalling pathway. These include the LEP, LEPR, MC4R, POMC and PCSK1 genes. A mutation with loss of function in one of these genes in homozygous carriers will cause disruption in this signalling pathway, resulting in monogenic obesity $[3,4,6]$. Approximately 140 variants in these genes associated with non-syndromic monogenic obesity are documented in the ClinVar (https:/ / www.ncbi.nlm.nih.gov/ClinVar (accessed on 3 January 2020)) and Ensembl (https: / / www.ensembl.org (accessed on 3 January 2020)) databases.

Most often, obesity has a polygenic and multifactorial origin. Polygenic, since it results from the presence of several common variants. When these variants are isolated, they have no or little metabolic effects, but when they are together, they increase the susceptibility to gain weight [7]. Multifactorial, since it is related not only to predisposing genetic factors, but also to the "obesogenic" environment, associated with a sedentary lifestyle (imbalance between intake and energy expenditure) and social and cultural factors. These non-genetic factors, such as nutrition and physical activity, also seem to have an impact on the modulation of gene activity, due to changes in the epigenetic signatures [3].

Therefore, the identification of variants associated with obesity is extremely relevant for differential diagnosis, for treatment selection in these patients and for prenatal diagnosis in families where a known variant was found.

Despite all the research studies already conducted, the aetiology of obesity is still far from being fully understood. The development of further studies, in order to identify new genes and variants involved in the regulation of body weight and obesity, and the study of their prevalence in a specific population, will allow us to move towards a future focused on the patient, with more effective prevention, follow-up and personalised treatment.

With this in mind, the primary aim of this research is to find new genetic variants linked to obesity and assess its prevalence in a Portuguese population.

\section{Materials and Methods}

We considered 65 genes (exons and exon-intron junctions), previously identified as risk factors for obesity development, which were sequenced by NGS, in a Portuguese group of obese/overweight individuals.

\subsection{Patient Selection}

The study sample consisted of 72 individuals (55 females, aged between 21 and 67 years and with a body mass index (BMI) between 26.9 and $68.0 \mathrm{~kg} / \mathrm{m}^{2}$, followed up at the Multidisciplinary Obesity Department of the Centro Hospitalar Universitário de Lisboa Central (Curry Cabral). The collection of the samples occurred after the individual signature of an informed consent. The protocol was approved by the Ethical Committee of ESTeSL (CE-ESTESL-No.41-2018).

\subsection{Laboratory Analysis}

Oral epithelium cells were collected with swab and DNA was extracted with ExtractMe kit ${ }^{\circledR}$ from BLIRT SA. The success of the extraction was evaluated by a fluorimetric method using the QuBit ${ }^{\circledR}$ equipment and the Qubit dsDNA high-sensitivity assay, from ThermoFisher Scientific (target-selective dyes bound to DNA and emit fluorescence). For all samples, some after 2 elutions, it was possible to reach the minimum concentration required for subsequent sequencing of the panel of 65 genes by NGS.

After obtaining the desired DNA concentrations, the libraries were prepared with TruSight One $\mathrm{kit}^{\circledR}$ from Illumina, Inc. (San Diego, CA, USA) respecting the manufacturer's instructions. Sequencing was performed on the NextSeq550 equipment from Illumina, Inc using the NextSeq 500/550 High Output Kit v2 (150 cycles).

The gene panel used includes genes associated with monogenic obesity and the leptin-melanocortin signalling pathway (LEP, LEPR, PCSK1, POMC and MC4R) [3], genes associated with insulin signalling pathway (IRS1, IRS2, IRS4 and SORCS1) [8-10], genes associated with lipid metabolism (ADRB1 and ADRB3, PRKAR1, PTEN and SPG11), [11-14] other genes associated with appetite regulation (BDNF, NTRK2, LRP2, MCHR1 and 
SLC6A14 [13-17] genes associated with syndromic obesity (ALMS1 and BBS family), among other genes previously associated with obesity (Table 1) [3,17-19].

Table 1. Gene panel (genes previously associated with obesity).

\begin{tabular}{cccccc}
\hline ADRB1 & BBS8/TTC8 & CPE & LRP2 & NTRK2 & SLC6A14 \\
\hline ADRB2 & BBS9 & FTO & MAGEL2 & PAX6 & SNRPN \\
ADRB3 & BBS10 & G6PC & MC3R & PCK1 & SORCS1 \\
ALMS1 & BBS11/TRIM32 & GNAS & MC4R & PCSK1 & SPG11 \\
BBS1 & BBS12 & IGF2 & MCHR1 & PHF6 & TBX3 \\
BBS2 & BBS13/MKS1 & IGF2R & MKRN3 & POMC & THRB \\
BBS3/ARL6 & BBS14/CEP290 & IRS1 & NDN & PPARG & TMEM67 \\
BBS4 & BBS15/WDPCP & IRS2 & NEGR1 & PRKAR1A & UCP1 \\
BBS5 & BBS17/LZTFL1 & IRS4 & NPY & PTEN & UCP2 \\
BBS6/MKKS & BDNF & LEP & NPY1R & SH2B1 & UCP3 \\
BBS7 & CCDC28B & LEPR & NPY2R & SIM1 & \\
\hline
\end{tabular}

\subsection{Data Analysis}

The analysis of the obtained data began with the pre-processing of the sequences, and the variant calling, in the Enrichment and BWA Enrichment applications of Illumina, Inc. For the variant annotation, the software Illumina Variant Studio 3.0 was used. Only variants detected in both applications (Enrichment and BWA Enrichment of Illumina, Inc.) and passing the PASS filter of Illumina Variant Studio 3.0, were considered for the continuation of the study. Variants outside exons and exon-intron regions (up to 12 bases) were also excluded.

To check the quality of readings, coverage and read depth, Software IGV-Integrative Genomics Viewer was used.

For the analysis of the identified variants, prediction of their impact and clinical relevance, we used ClinVar (NCBI), a public database, where associations between human genetic variants and phenotypes, scientifically based, are reported, and PolyPhen-2, a software available online, which predicts the possible impact of amino acid substitutions on the stability and function of human proteins. In this software, SNPs are functionally annotated, coding SNPs are mapped to gene transcripts, protein sequence annotations and structural attributes are extracted and conservation profiles are developed. The probability of the missense mutation being harmful is then calculated using a combination of these properties. In Polyphen, we can find two variant classifiers, HumDIV and HumVAR. Only predictions from HumDIV will be presented in this study, since is considered preferential for rare alleles [20]. We also resort to the Human Splicing Finder to evaluate the impact on splicing, of intron, missense and synonymous variants located in splicing regions (1-3 bases of the exon, 1-8 bases of the intron).

To identify risk variants associated with obesity, the frequencies of the variants identified in this study were compared with European and Global frequencies in the 1000 Genomes project (https://www.internationalgenome.org (accessed on 6 January 2020) and, when not reported, in TopMed (https://www.nhlbiwgs.org/ (accessed on 6 January 2020). To be considered a risk allele, the difference between the frequency in the studied sample and the European and Global reference frequency had to be equal to or greater than $1.41 \%$ (corresponding to the proportion of two alleles in the calculated sample frequency $-2 /(2 \times 71))$.

\section{Results}

Of the 72 samples analysed, a coverage smaller than $80 \%$ was obtained in eight samples. After applying the PASS filter Illumina Variant Studio, variants were detected in all samples, except for one. The use of a non-invasive method for sample collection (oral epithelium cells collected with swabs) was probably the reason for the low coverage detected in these samples. To perform the technique, it was necessary to obtain a DNA 
concentration higher than $5 \mathrm{ng} / \mu \mathrm{L}$ per sample, which for some samples was only possible after a second extraction and elution. Effectively, the efficiency of DNA recovery and extraction from swabs is usually, regardless of the material, less than $50 \%$ [21].

Globally, 429 different variants were identified in 63 of the 65 genes under study: 423 snv's (single nucleotide variant), $1 \mathrm{mnv}$ (multiple nucleotide variant), 2 insertions and 3 deletions. In absolute numbers, 4348 variants were detected: 4318 snv's, 6 mnv's, 21 insertions and 3 deletions.

No variants were detected in PHF6 and PTEN genes. After verifying the mean coverage value of these sequences, we could rule out the suspicion of inefficacy of the enrichment probes.

\subsection{Variant Consequences}

Analysing the 429 different variants identified (Table 2), missense variants were the most frequent, counting $48.25 \%$, followed by the synonymous variants with $41.49 \%$. According to the 1000 Genomes Project, $52.09 \%$ of these variants have a European prevalence of less than $1 \%$.

Table 2. Variants classified by consequence.

\begin{tabular}{ccc}
\hline Variant Consequences & Number of Variants & $\begin{array}{c}\text { Number of Variants with a European } \\
\text { Prevalence }<\mathbf{1} \text { According to the } \\
\text { 1000 Genomes Project }\end{array}$ \\
\hline Missense variant & 207 & 122 \\
Synonymous variant & 178 & 75 \\
Intron variant & 38 & 23 \\
$3^{\prime}$ prime UTR variant & 3 & 0 \\
Nonsense variant & 2 & 2 \\
Frameshift variant & 1 & 1 \\
Inframe deletion & 1 & 1 \\
Inframe insertion & 1 & 0 \\
\hline
\end{tabular}

According to PolyPhen HumDIV, of the 207 missense variants identified, 125 are predicted to be benign, 35 are possibly damaging and 44 probably damaging. Three variants have unknown impact. In absolute numbers, 1701 missense variants were detected, 1435 benign, 117 possibly damaging and 145 probably damaging.

Table 3 describes the clinical associations that may be related to obesity, the number of variants identified and the number of samples where these variants were detected.

Table 3. Clinical association of the identified variants potentially associated with obesity.

\begin{tabular}{cccc}
\hline Clinical Associations & $\begin{array}{c}\text { Number of } \\
\text { Different Variants }\end{array}$ & $\begin{array}{c}\text { Total Number of } \\
\text { Variants }\end{array}$ & $\begin{array}{c}\text { Number of } \\
\text { Samples }\end{array}$ \\
\hline Obesity Susceptibility & 3 & 44 & 35 \\
Obesity & 5 & 40 & 34 \\
Monogenic obesity & 13 & 228 & 66 \\
Syndromic obesity & 94 & 671 & 71 \\
Childhood obesity & 2 & 13 & 13 \\
Type 2 Diabetes Mellitus & 5 & 45 & 32 \\
Monogenic Diabetes & 12 & 26 & 20 \\
Insulin resistance & 2 & 23 & 20 \\
Influence on BMI & 3 & 35 & 23 \\
Leptin deficiency or disfunction & 2 & 3 & 3 \\
Leptin receptor deficiency & 5 & 138 & 59 \\
Metabolic syndrome & 2 & 77 & 27 \\
susceptibility & 3 & 27 & \\
Thyroid hormone resistance & 5 & &
\end{tabular}


A total of 129 variants are potentially associated with obesity, according to ClinVar and the consulted bibliography, some of which have more than a clinical association. Of these variants, seven are classified as a risk factor, one is classified as probably pathogenic and three as pathogenic (Table 4).

Table 4. Clinical association of the identified variants potentially associated with obesity.

\begin{tabular}{ccccccc}
\hline Gene & dbSNP ID & Ho & He & ClinVar & Disease & $\begin{array}{c}\text { PolyPhen } \\
\text { HumDIV }\end{array}$ \\
\hline ADRB2 & rs1042713 & 23 & 23 & Risk factor & Metabolic syndrome & Benign \\
ADRB2 & rs1042714 & 31 & 20 & Risk factor & Metabolic syndrome, obesity & Benign \\
ADRB3 & rs4994 & 0 & 10 & Risk factor & Obesity & Benign \\
IRS1 & rs1801278 & 1 & 11 & Risk factor & Insulin resistance & Possibly damaging \\
IRS2 & rs1805097 & 2 & 20 & Risk factor & Diabetes Mellitus & - \\
PCSK1 & rs6232 & 0 & 5 & Risk factor & Obesity & Benign \\
POMC & rs28932472 & 0 & 2 & Risk factor & Early-onset obesity & Probably damaging \\
BBS2 & rs773417074 & 0 & 1 & Prob pathogenic & Bardet-Biedl syndrome & - \\
MKKS & rs74315394 & 0 & 1 & Pathogenic & Mckusick Kaufman syndrome & Probably damaging \\
SPG11 & rs199588440 & 0 & 1 & Pathogenic & Spastic paraplegia 11 & \\
UCP3 & rs2229707 & 0 & 1 & Pathogenic & Severe obesity, T2 Diabetes & Benign \\
\hline
\end{tabular}

Ho-homozygotic; He-Heterozygotic.

\subsection{Variant Incidence}

Of the 65 genes studied and considering the 64 samples with coverage greater than $80.00 \%$, in three genes, variants were found in $100 \%$ of the samples: ALMS1, LRP2 and NEGR1 (Figure 1), followed by the BBS4 and PCK1 genes, with variants in $98.44 \%$ of the samples.

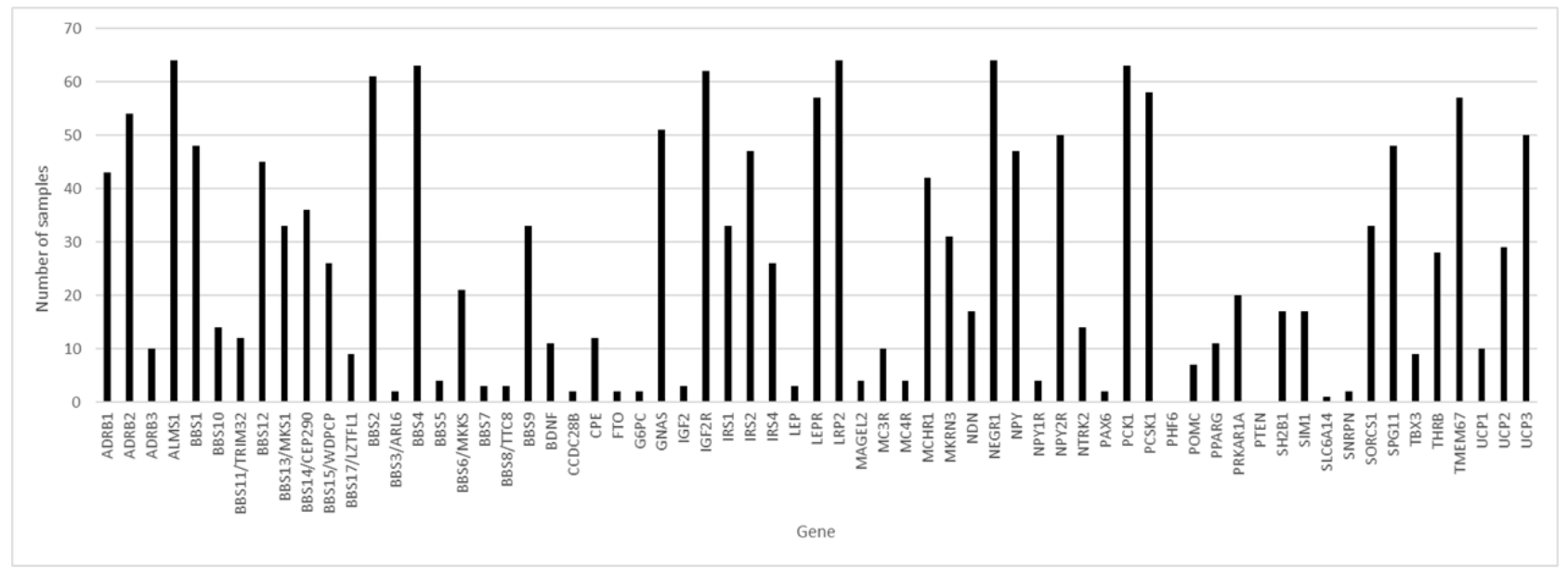

Figure 1. Number of samples where variants were detected, by gene. The $\mathrm{Y}$ axis represents the number of samples, and the $\mathrm{X}$ axis the name of genes.

Of all the identified variants, $16.80 \%$ were found in the LRP2 gene and $11.66 \%$ in the ALMS1 gene (Figure 2). 


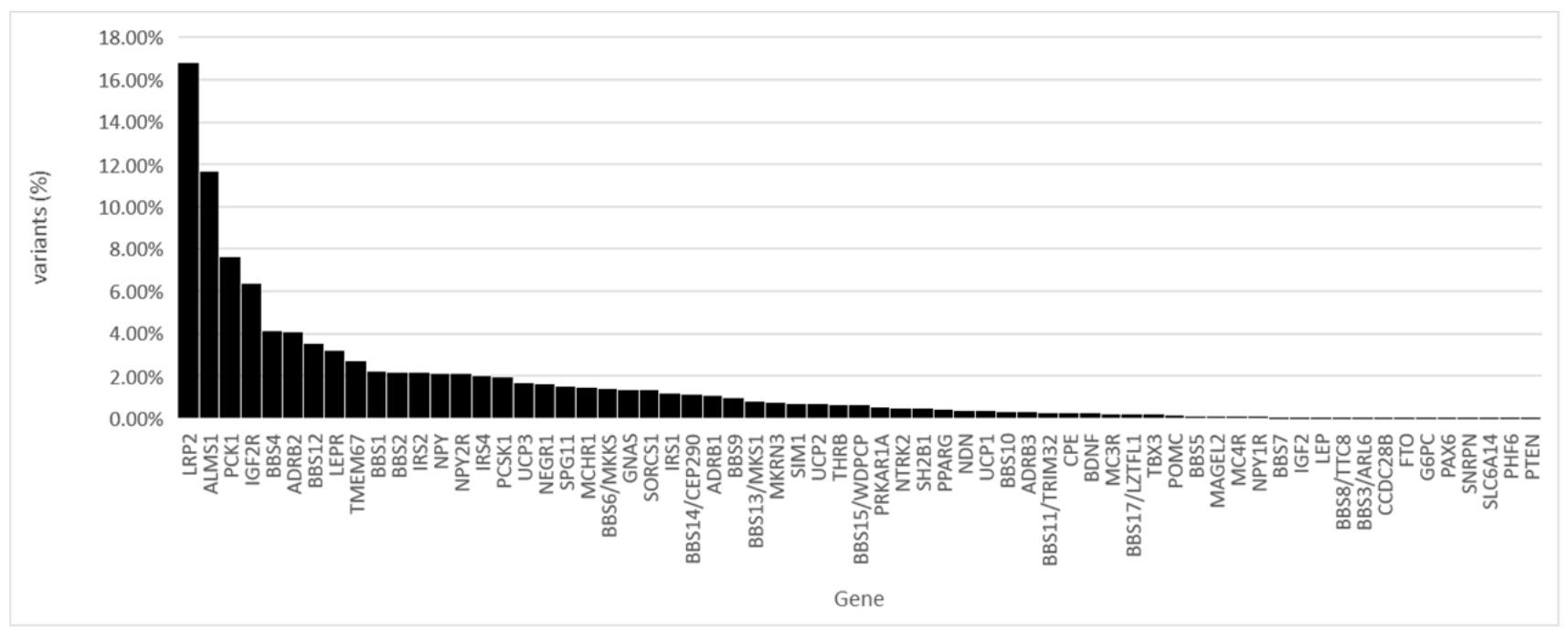

Figure 2. Percentage of samples where variants were detected, by gene. The $\mathrm{Y}$ axis represents the percentage of samples with variability, and the $\mathrm{X}$ axis the name of the genes.

In the 64 samples, we found variants in an average of 26.69 genes and an average of 66.2 variants per sample.

\subsection{Identification of Potential Risk Alleles}

The identified potential risk alleles associated with obesity are described in Table 5 .

Table 5. Potential risk alleles associated with obesity.

\begin{tabular}{|c|c|c|c|c|c|c|}
\hline \multirow{2}{*}{$\begin{array}{c}\text { Gene } \\
\text { ADRB2 }\end{array}$} & \multirow{2}{*}{$\begin{array}{c}\text { dbSNP ID } \\
\text { rs1800888 }\end{array}$} & \multicolumn{2}{|c|}{ Variant } & \multirow{2}{*}{$\begin{array}{c}\text { Freq (\%) } \\
3.52\end{array}$} & \multirow{2}{*}{$\frac{\text { Eur Freq (\%) }}{1.79}$} & \multirow{2}{*}{$\begin{array}{c}\text { G1 Freq (\%) } \\
0.40\end{array}$} \\
\hline & & c. $491 \mathrm{C}>\mathrm{T}$ & p.Thr164Ile & & & \\
\hline ALMS1 & rs41291187 & c. $1868 \mathrm{~A}>\mathrm{G}$ & p.His623Arg & 3.52 & 2.09 & 0.70 \\
\hline BBS9 & rs11773504 & c. $1363 \mathrm{G}>\mathrm{A}$ & p.Ala455Thr & 21.83 & 19.58 & 17.13 \\
\hline IGF2R & rs76130099 & c. $5701 \mathrm{G}>\mathrm{A}$ & p.Val1901Ile & 2.11 & 0.60 & 0.42 \\
\hline IGF2R & rs2297367 & c. $6995+6 C>T$ & & 10.56 & 4.87 & 7.09 \\
\hline IRS1 & rs2234931 & c.702G >A & c.702G >A(p. =) & 11.27 & 8.55 & 5.29 \\
\hline LRP2 & rs147058423 & c.3110G $>\mathrm{A}$ & p.Arg1037Lys & 1.41 & 0.10 & 0.02 \\
\hline LRP2 & rs189273089 & c. $9592 \mathrm{G}>\mathrm{A}$ & p.Glu3198Lys & 1.41 & 0.00 & 0.04 \\
\hline LRP2 & rs41268685 & c. $13250 \mathrm{G}>\mathrm{A}$ & p.Gly4417Asp & 2.82 & 1.19 & 0.58 \\
\hline LRP2 & rs183867145 & c. $894 \mathrm{~A}>\mathrm{G}$ & c. $894 \mathrm{~A}>\mathrm{G}(\mathrm{p} .=)$ & 1.41 & 0.00 & 0.02 \\
\hline LRP2 & rs34104660 & c. $402 C>A$ & c. $402 \mathrm{C}>\mathrm{A}(\mathrm{p} .=)$ & 9.86 & 8.15 & 4.75 \\
\hline LRP2 & rs33954745 & c. $2376 \mathrm{~T}>\mathrm{C}$ & c. $2376 \mathrm{~T}>\mathrm{C}(\mathrm{p} .=)$ & 9.86 & 8.45 & 7.63 \\
\hline NPY1R & rs5578 & c. $1121 \mathrm{~A}>\mathrm{C}$ & p.Lys374Thr & 2.82 & 0.69 & 0.30 \\
\hline NTRK2 & rs2289657 & c. $1848 \mathrm{C}>\mathrm{A}$ & c. $1848 \mathrm{C}>\mathrm{A}($ p. $=)$ & 8.45 & 4.37 & 5.81 \\
\hline POMC & rs 80326661 & c. $641 \mathrm{~A}>\mathrm{G}$ & p.Glu214Gly & 2.11 & 0.69 & 0.14 \\
\hline SPG11 & rs80338869 & c. $7023 \mathrm{C}>\mathrm{T}$ & c. $7023 \mathrm{C}>\mathrm{T}(\mathrm{p} .=)$ & 7.04 & 3.18 & 1.18 \\
\hline SPG11 & rs79708848 & c. $1698 \mathrm{~T}>\mathrm{G}$ & p.Asp566Glu & 2.82 & 1.39 & 0.52 \\
\hline TMEM67 & rs117195541 & c. $2397 \mathrm{~T}>\mathrm{C}$ & c. $2397 \mathrm{~T}>\mathrm{C}(\mathrm{p} .=)$ & 2.82 & 1.39 & 0.84 \\
\hline
\end{tabular}

Freq-Frequency in the studied sample; Eur Freq-European frequency according to 1000 Genome Project; Gl Freq-Global Frequency according to the 1000 Genome Project.

Although they did not fully meet the criteria defined previously, variants rs183867145, rs147058423 and rs189273089 (found in LRP2 gene) were also considered as potential risk variants associated with obesity. Effectively, according to the 1000 Genomes Project, variant rs183867145 was only identified in one American heterozygous individual, variant rs147058423 in a European heterozygous individual and variant rs189273089 in two heterozygous carriers, one American and one African. The three variants were detected each in two individuals in our sample. 
In five variants, the frequency of the minor allele in the sample was lower than the European and Global frequencies, according to 1000 Genomes project (Table 6). These findings suggest that the c.724-8G allele of the BBS1 gene, c.196G of the BDNF gene, c.2512A of the BBS14/CEP290 gene, c.745C of the IGF2R gene and c.84T of the SLC6A14 gene constitute potential risk alleles for obesity.

Table 6. Variants in which the frequency of the minor allele is lower than European/global frequencies.

\begin{tabular}{ccccccc}
\hline Gene & dbSNP ID & \multicolumn{2}{c}{ Variant } & Freq (\%) & Eur Freq (\%) & G1 Freq (\%) \\
\hline BBS1 & rs10896125 & c.724-8G>C & & 17.90 & 23.96 & 24.26 \\
BBS14/CEP290 & rs11104738 & c.2512A $>$ G & p.Lys838Glu & 2.86 & 4.87 & 9.70 \\
BDNF & rs6265 & c.196G>A & p.Val66Met & 8.73 & 19.68 & 20.13 \\
IGF2R & rs8191754 & c.754C>G & p.Leu252Val & 12.14 & 14.81 & 16.03 \\
SLC6A14 & rs12720074 & c.84T>A & c.84T>A(p. =) & 0.82 & 9.66 & 5.40 \\
\hline
\end{tabular}

Freq-Frequency in the studied sample; Eur Freq.-European frequency according to 1000 Genome Project; Gl Freq.-Global Frequency according to the 1000 Genome Project.

\subsection{New Variants}

In the variant analysis, six new variants were detected, all in heterozygous carriers. These variants, localised in genes ALMS1, BBS1, SORCS1 and TMEM67 were not referenced in the consulted databases. The variant c.5552C > T, in the ALMS1 gene, results in a missense variant, where a Proline is replaced by a Leucine in the amino acid 1851. This variant has a PolyPhen prediction of possibly damaging. The variant c.1437C $>\mathrm{T}$, in the BBS1 gene, results in a synonymous variant. The variant c.1072A $>G$, in the SORCS1 gene, results in a missense variant, where an Arginine is replaced by a Glycine in the amino acid 358. This variant has a PolyPhen prediction of possibly damaging. The variant c.2491A>C, in the SORCS1 gene, results in a missense variant, where a Threonine is replaced by a Proline in the amino acid 831. This variant has a PolyPhen prediction of probably damaging. The variant c.158A $>\mathrm{G}$, in gene TMEM67, results in a missense variant, where a Glutamine is replaced by an Arginine in the amino acid 53. This variant has a PolyPhen prediction of benign. The variant c.2583T $>C$, in gene TMEM67, results in a synonymous variant.

To validate these results, functional studies should be performed.

\section{Discussion}

In the 72 individuals studied, no cases of monogenic obesity were recognised. In all samples, several variants were identified that constitute risk factors associated with obesity (between 3 and 12 variants per individual), which may influence the development of this phenotype in these individuals.

Of all the variants identified in this study, only five (Table 7), found in heterozygous carriers, have a ClinVar classification of pathogenic or probably pathogenic.

Table 7. Pathogenic or probably pathogenic variants identified.

\begin{tabular}{|c|c|c|c|c|c|}
\hline Gene & dbSNP ID & Variant & ClinVar & Disease & PolyPhen HumDIV \\
\hline BBS2 & rs773417074 & $\begin{array}{c}\text { c.627_628delTT } \\
\text { p.Cys210SerfsTer20 }\end{array}$ & $\begin{array}{l}\text { Probably } \\
\text { Pathogenic }\end{array}$ & Bardet-Biedl syndrome & - \\
\hline LRP2 & rs138269726 & c.6160G >A p.Asp2054Asn & Pathogenic & Donnai Barrow syndrome & Probably damaging \\
\hline MKKS & rs74315394 & c.724G > T p.Ala242Ser & Pathogenic & $\begin{array}{c}\text { Mckusick Kaufman } \\
\text { syndrome }\end{array}$ & Probably damaging \\
\hline SPG11 & rs199588440 & c.1951C > T p.Arg651Ter & Pathogenic & Spastic paraplegia 11 & - \\
\hline UCP3 & rs2229707 & c.304G>Ap.Val102Ile & Pathogenic & $\begin{array}{l}\text { Severe obesity, T2 } \\
\text { Diabetes }\end{array}$ & Benign \\
\hline
\end{tabular}

The four syndromes referenced in Table 6 have autosomal recessive transmission, and, with the exception of the Donnai-Barrow Syndrome, obesity may be part of the phenotype $[14,22,23]$. The variant rs2229707 is described as associated with severe obesity and 
was detected in a study conducted by Argyropoulos et al., in an obese woman in heterozygosity (39 years), in three obese descendants in homozygosity (11, 14 and 20 years-BMI is higher in older individuals) and in a non-obese descendant (9 years) in heterozygosity [24]. The information from this study and the other consulted bibliography is not enough to define whether this mutation may be associated with monogenic obesity and whether it has autosomal dominant or recessive heredity. In one of our samples, this variant was detected along with another possibly damaging variant in the UCP3 gene (rs8179180), both in heterozygosity. This sample belongs to an obese woman, whose father and mother, three siblings and two children are obese. It would be interesting to carry out the same study, sequencing the 65 genes, to all family members (including non-obese family members, who are not included in the available family history). Thus, we could test the penetrance and evaluate the clinical significance, and association with obesity, of these two variants identified in the UCP3 gene.

\section{Limitations}

One of the limitations of this study was the use of a sample collected by a non-invasive method (samples of oral epithelium cells collected by swab). This was probably the reason for the low coverage detected in some samples and the lack of results in one of the samples. The chosen NGS technique also failed to detect chromosomal structural changes such as massive deletions, insertions, inversions, or duplications, as well as epigenetic changes that may have occurred $[9,25]$. The lack of detailed clinical and family history of the individuals under study, namely associated co-morbidities, cases of childhood obesity or the identification of non-obese family members, and the non-sequencing of samples of relatives (ascending and descending), hindered the interpretation of the found variants, although it would help in the establishment of correlations between alleles and phenotypes. The variant frequency analysis was also hampered by the lack of a control group and the use of a database, the 1000 Genomes Project, in which obesity was not an exclusion criterion and there was no representation from Portugal [26].

\section{Final Considerations}

This study aimed to identify new genetic variants associated with obesity and to determine its prevalence in the Portuguese population. The development of similar studies may allow in the future to easily identify individuals at high risk of developing obesity in order to define more effective preventive strategies. In that sense, it will allow personalised medicine to be applied to the obesity field.

Author Contributions: Study design and conceptualization of study: M.B., J.S.-N. and L.V. Sample collection: J.S.-N. DNA extraction, library preparation and sequencing: M.B., B.S. and C.G. Data analysis: M.B., C.G. and B.S. Writing of the manuscript: M.B. and C.G. All authors have read and agreed to the published version of the manuscript.

Funding: This research was funded by Instituto Politécnico de Lisboa by IDI\&CA project IPL/2017/ genetobese/ESTeSL. Fundação Para a Ciência e Tecnologia, Portugal: FCT/MCTES (UIDB/05608/2020 and UIDP/05608/2020)-H\&TRC.

Institutional Review Board Statement: The protocol was approved by the Ethical Committee of ESTeSL (CE-ESTESL-No.41-2018). The collection of the samples occurred after the individual signature of an informed consent. Research has been performed in accordance with the Declaration of Helsinki.

Informed Consent Statement: Informed consent was obtained from all subjects involved in the study.

Data Availability Statement: The datasets used and analysed during the current study are available from the corresponding author on reasonable request.

Conflicts of Interest: None of the authors have any potential conflicts of interest associated with this research. 


\section{References}

1. World Health Organization-Obesity and Overweight. Available online: http://www.who.int/en/news-room/fact-sheets/ detail/obesity-and-overweight (accessed on 6 June 2020).

2. Inquérito Alimentar Nacional e de Atividade Física, IAN-AF 2015-2016. Available online: https://ian-af.up.pt/sites/default/ files/IAN-AFRelatórioResultados_0.pdf (accessed on 1 November 2020).

3. Rohde, K.; Keller, M.; Poulsen, L.L.C.; Blüher, M.; Kovacs, P.; Böttcher, Y. Genetics and epigenetics in obesity. Metabolism 2019, 92, 37-50. [CrossRef]

4. Stefano, P.; Giuseppe, P.; Barbara, P.; Irene, D.C.; Giacinto, A.D.M.; Barbara, A.; Andrea, S.; Valeria, V.; Giuseppina, M.; Lucilla, G.; et al. Mendelian non-syndromic obesity. Acta Biomed 2019, 90, 87-89.

5. Baxter, J.; Armijo, P.R.; Flores, L.; Krause, C.; Samreen, S.; Tanner, T. Updates on Monogenic Obesity in a Multifactorial Disease. Obes. Surg. 2019, 29, 4077-4083. [CrossRef]

6. Saeed, S.; Bonnefond, A.; Manzoor, J.; Shabir, F.; Ayesha, H.; Philippe, J.; Durand, E.; Crouch, H.; Sand, O.; Ali, M.; et al. Genetic variants in LEP, LEPR, and MC4R explain 30\% of severe obesity in children from a consanguineous population. Obesity 2015, 23, 1687-1695. [CrossRef]

7. Loos, R.J.; Janssens, A.C.J. Predicting Polygenic Obesity Using Genetic Information. Cell Metab. 2017, 25, 535-543. [CrossRef]

8. Nunziata, A.; Funcke, J.-B.; Borck, G.; Von Schnurbein, J.; Brandt, S.; Lennerz, B.; Moepps, B.; Gierschik, P.; Fischer-Posovszky, P.; Wabitsch, M. Functional and Phenotypic Characteristics of Human Leptin Receptor Mutations. J. Endocr. Soc. 2019, 3, 27-41. [CrossRef]

9. Yohe, S.; Thyagarajan, B. Review of Clinical Next-Generation Sequencing. Arch. Pathol. Lab. Med. 2017, 141, 1544-1557. [CrossRef] [PubMed]

10. Subkhangulova, A.; Malik, A.R.; Hermey, G.; Popp, O.; Dittmar, G.; Rathjen, T.; Poy, M.N.; Stumpf, A.; Beed, P.S.; Schmitz, D.; et al. SORCS 1 and SORCS 3 control energy balance and orexigenic peptide production. EMBO Rep. 2018, 19, 1-18. [CrossRef]

11. Masuo, K.; Lambert, G.W. Relationships of Adrenoceptor Polymorphisms with Obesity. J. Obes. 2011, 2011, 1-10. [CrossRef] [PubMed]

12. London, E.; Rothenbuhler, A.; Lodish, M.; Gourgari, E.; Keil, M.; Lyssikatos, C.; de la Luz Sierra, M.; Patronas, N.; Maria Nesterova, M.; Stratakis, C.A. Differences in adiposity in cushing syndrome caused by PRKAR1A mutations: Clues for the role of cyclic AMP signaling in obesity and diagnostic implications. J. Clin. Endocrinol. Metab. 2014, 99, 303-310. [CrossRef] [PubMed]

13. Chen, C.-Y.; Chen, J.; He, L.; Stiles, B.L. PTEN: Tumor Suppressor and Metabolic Regulator. Front. Endocrinol. 2018, 9, 338. [CrossRef]

14. Boutry, M.; Pierga, A.; Matusiak, R.; Branchu, J.; Houllegatte, M.; Ibrahim, Y.; Balse, E.; El Hachimi, K.-H.; Brice, A.; Stevanin, G.; et al. Loss of spatacsin impairs cholesterol trafficking and calcium homeostasis. Commun. Biol. 2019, 2, 1-13. [CrossRef]

15. Stahel, P.; Sud, S.K.; Lee, S.J.; Jackson, T.; Urbach, D.R.; Okrainec, A.; Allard, J.P.; Bassett, A.S.; Paterson, A.D.; Sockalingam, S.; et al . Phenotypic and genetic analysis of an adult cohort with extreme obesity. Int. J. Obes. 2018, 43, 2057-2065. [CrossRef] [PubMed]

16. Da Fonseca, A.C.P.; Mastronardi, C.; Johar, A.; Arcos-Burgos, M.; Paz-Filho, G. Genetics of non-syndromic childhood obesity and the use of high-throughput DNA sequencing technologies. J. Diabetes Complicat. 2017, 31, 1549-1561. [CrossRef]

17. Fontaine-Bisson, B.; Thorburn, J.; Gregory, A.; Zhang, H.; Sun, G. Melanin-concentrating hormone receptor 1 polymorphisms are associated with components of energy balance in the Complex Diseases in the Newfoundland Population: Environment and Genetics (CODING) study. Am. J. Clin. Nutr. 2013, 99, 384-391. [CrossRef] [PubMed]

18. Hearn, T. ALMS1 and Alström syndrome: A recessive form of metabolic, neurosensory and cardiac deficits. J. Mol. Med. 2019, 97, 1-17. [CrossRef] [PubMed]

19. Suviolahti, E.; Oksanen, L.J.; Öhman, M.; Cantor, R.M.; Ridderstråle, M.; Tuomi, T.; Kaprio, J.; Rissanen, A.; Mustajoki, P.; Jousilahti, P.; et al. The SLC6A14 gene shows evidence of association with obesity. J. Clin. Investig. 2003, 112, 1762-1772. [CrossRef] [PubMed]

20. Adzhubei, I.; Jordan, D.M.; Sunyaev, S.R. Predicting Functional Effect of Human Missense Mutations Using PolyPhen-2. Curr. Protoc. Hum. Genet. 2013, 76, 7.20.1-7.20.41. [CrossRef] [PubMed]

21. Bruijns, B.B.; Tiggelaar, R.M.; Gardeniers, H. The Extraction and Recovery Efficiency of Pure DNA for Different Types of Swabs. J. Forensic Sci. 2018, 63, 1492-1499. [CrossRef] [PubMed]

22. Braun, D.A.; Hildebrandt, F. Ciliopathies. Cold Spring Harb. Perspect. Biol. 2017, 9, a028191. [CrossRef]

23. Khalifa, O.; Al-Sahlawi, Z.; Imtiaz, F.; Ramzan, K.; Allam, R.; Al-Mostafa, A.; Abdel-Fattah, M.; Abuharb, G.; Nester, M.; Verloes, A.; et al. Variable expression pattern in Donnai-Barrow syndrome: Report of two novel LRP2 mutations and review of the literature. Eur. J. Med. Genet. 2015, 58, 293-299. [CrossRef] [PubMed]

24. Argyropoulos, G.; Brown, A.M.; Willi, S.M.; Zhu, J.; He, Y.; Reitman, M.; Gevao, S.M.; Spruill, I.; Garvey, W.T. Effects of mutations in the human uncoupling protein 3 gene on the respiratory quotient and fat oxidation in severe obesity and type 2 diabetes. $J$. Clin. Investig. 1998, 102, 1345-1351. [CrossRef] [PubMed]

25. Kleinendorst, L.; Massink, M.P.G.; Cooiman, M.I.; Savas, M.; Van Der Baan-Slootweg, O.H.; Roelants, R.J.; Janssen, I.C.M.; Meijers-Heijboer, H.J.; Knoers, N.V.A.M.; Van Amstel, H.K.P.; et al. Genetic obesity: Next-generation sequencing results of 1230 patients with obesity. J. Med. Genet. 2018, 55, 578-586. [CrossRef] [PubMed]

26. 1000 Genomes Project Consortium; Auton, A.; Abecasis, G.R.; Altshuler, D.M.; Durbin, R.M.; Bentley, D.R.; Chakravarti, A. A global reference for human genetic variation. Nature 2015, 526, 68-74. [PubMed] 